\title{
Role of HCV Core gene of genotype 1a and 3a and host gene Cox-2 in HCV-induced pathogenesis
}

\author{
Shah Jahan, Saba Khaliq, Bushra ljaz, Waqar Ahmad and Sajida Hassan*
}

\begin{abstract}
Background: Hepatitis C virus (HCV) Core protein is thought to trigger activation of multiple signaling pathways and play a significant role in the alteration of cellular gene expression responsible for HCV pathogenesis leading to hepatocellular carcinoma (HCC). However, the exact molecular mechanism of HCV genome specific pathogenesis remains unclear. We examined the in vitro effects of HCV Core protein of HCV genotype 3a and 1a on the cellular genes involved in oxidative stress and angiogenesis. We also studied the ability of HCV Core and Cox-2 siRNA either alone or in combination to inhibit viral replication and cell proliferation in HCV serum infected Huh-7 cells.

Results: Over expression of Core gene of HCV 3a genotype showed stronger effect in regulating RNA and protein levels of Cox-2, iNOS, VEGF, p-Akt as compared to HCV-1a Core in hepatocellular carcinoma cell line Huh-7 accompanied by enhanced PGE2 release and cell proliferation. We also observed higher expression levels of above genes in HCV 3a patient's blood and biopsy samples. Interestingly, the Core and Cox-2-specific siRNAs down regulated the Core 3a-enhanced expression of Cox-2, iNOS, VEGF, p-Akt. Furthermore, the combined siRNA treatment also showed a dramatic reduction in viral titer and expression of these genes in HCV serum-infected Huh-7 cells. Taken together, these results demonstrated a differential response by HCV 3a genotype in HCVinduced pathogenesis, which may be due to Core and host factor Cox-2 individually or in combination.

Conclusions: Collectively, these studies not only suggest a genotype-specific interaction between key players of $\mathrm{HCV}$ pathogenesis but also may represent combined viral and host gene silencing as a potential therapeutic strategy.
\end{abstract}

\section{Background}

An estimated 3\% of the world's population is chronically infected with Hepatitis $\mathrm{C}$ virus (HCV) which is the main cause of liver fibrosis and cirrhosis, often leading to HCC (hepatocellular carcinoma) in a substantial number of patients. Almost 10 million people in Pakistan are living with $\mathrm{HCV}[1,2]$. The most prevalent $\mathrm{HCV}$ genotype in Pakistan is 3 a followed by $1 \mathrm{a}$ [3]. HCV virion is enveloped and has a positive strand genome comprising $9.6 \mathrm{~kb}$ RNA which is processed by cellular and viral proteases into 10 viral proteins, Core, E1, E2, p7 (structural proteins), NS2, NS3, NS4a, NS4b, NS5a and NS5b (nonstructural proteins). Although specific mechanisms by which $\mathrm{HCV}$ disease progresses remains unknown, direct

\footnotetext{
* Correspondence: sajihassan2004@yahoo.com

Applied and Functional Genomics Laboratory, National Centre of Excellence in Molecular Biology, University of Punjab, Lahore 53700, Pakistan
}

interaction of specific viral proteins with host cell system has shown to be accounted for some of its pathophysiological profile of $\mathrm{HCV}$ patients [4].

Besides nucleocaspid formation, HCV Core protein, in particular, also modulates gene transcription, cell proliferation, cell death and interferes with metabolism leading to oxidative stress, liver steatosis and eventually HCC. Oxidative stress has emerged as a key contributor in the development and progression of HCV-induced pathogenesis of liver [5,6]. Several factors might contribute to oxidative stress associated with $\mathrm{HCC}$, as $\mathrm{HCV}$ Core and NS5a proteins, which are able to up-regulate Cox-2 expression; a key player of oxidative stress in hepatocytes derived cells [7]. The expression of Cox-2 in $\mathrm{HCC}$ was found to correlate with the levels of several key molecules implicated in carcinogenesis such as iNOS (induced nitric oxide synthase), VEGF (vascular

\section{C)


endothelial growth factor) and p-Akt $[8,9]$. iNOS and Cox-2 have carcinogenic effects achieved either directly or by producing mediator that regulate cellular growth [10]. Cox-2 can induce angiogenesis growth factors via VEGF in HCV associated HCC $[9,11,12]$. A number of other inflammatory mediators including nitric oxide (NO), Cox-2, and prostaglandin E2 (PGE2) in cultured hepatocellular carcinoma cells also stimulate VEGF [11]. Cox-2 activates Akt in human HCC via a p13-kinasedependent mechanism [13], it acts as an important signal mediator, which regulates cell survival and proliferation $[14,15]$. Despite several studies, mechanisms involved in $\mathrm{HCV}$-associated pathogenesis are not completely understood; it may vary as a function of viral genotype [16].

Very few studies have been undertaken to evaluate the role of HCV Core protein of genotype $3 \mathrm{a}$ and $1 \mathrm{a}$ in $\mathrm{HCV}$ induced pathogenesis. In this study, we selected Huh-7 cells as culture model system for the transient transfection using $\mathrm{HCV}$ 3a and 1a Core genes and viral load analysis using HCV-infected serum as inoculum. We found a greater effect of HCV Core of genotype 3a on the expression levels of Cox-2, iNOS, VEGF, p-Akt in transiently expressing Core protein and in seruminfected Huh-7 cells as well as in patient's blood and liver biopsies samples. Although, HCV Core protein is highly conserved between different genotypes, we observed differences in the HCV Core region of $1 \mathrm{a}$ and 3a and speculate that these differences may differentially regulate hepatic pathogenesis in $\mathrm{HCV}$ infected individuals.

HCV RNA is highly susceptible to RNAi-induced suppression, as many investigators have reported the inhibition of HCV RNA levels by targeting different genes using RNAi. In our previous study, we used siRNA against HCV 3a Core and inhibited its expression not only in transiently transfected cells but also in serum infected Huh-7 cells [17]. Here, we used siRNA against Core and Cox-2 genes either alone or in combination with HCV 3 a Core gene-transfected and serum-infected Huh-7 cells to further study HCVinduced pathogenesis. We observed additional inhibitory effect of HCV Core and Cox-2 silencing on the expression levels of genes involved in $\mathrm{HCV}$ pathogenesis, suggesting a possible virus host interaction among these, moreover, reduction of viral titer may also represent potential combinational therapeutic approach against $\mathrm{HCV}$ infection.

\section{Results}

\section{Role of HCV Core in HCV induced pathogenesis}

HCV 1a and 3a Core genes were cloned into pCR3.1/ FLAG tag (Figure 1A). The amino acid sequence comparison showed that 3a Core protein has $90 \%$ similarity

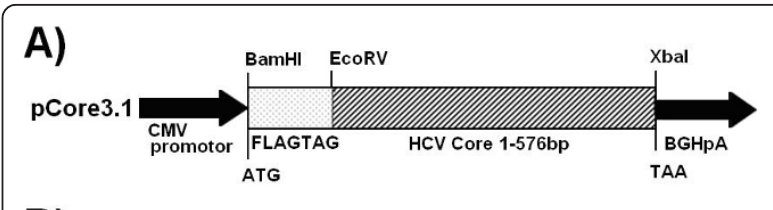

B)

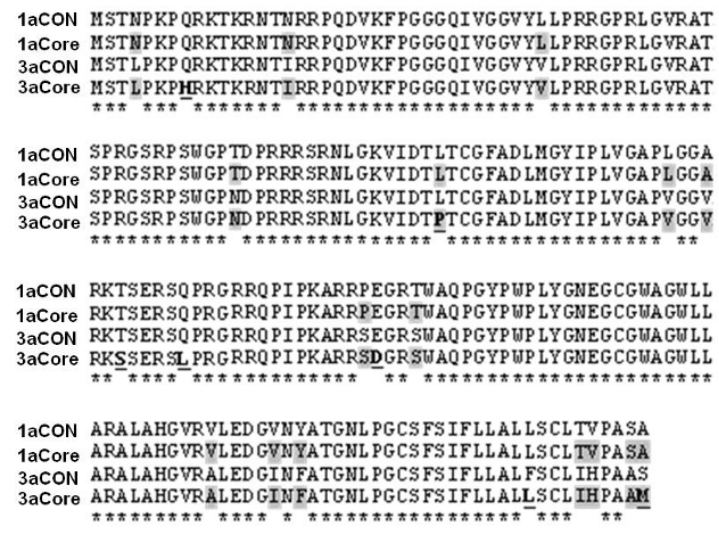

Figure $1 \mathrm{HCV}$ Core expression plasmids and protein sequences comparison of HCV genotype $1 \mathrm{a}$ and 3a. A) Schematic diagram of HCV Core expression plasmid illustrating the FLAG tag sequences having ATG start site and with HCV3a and 1a Core (1-573 bp) sequence insertion into mammalian expression plasmid pCR3.1. The CMV promoter and BGHpA regions of pCR3.1 are also shown. (B) Amino acid sequence comparison of HCV Core 1a and 3a clones. Comparison of full predicted amino acid sequence of HCV Core isolates in our study against a consensus genotype 3a clone ( $3 \mathrm{aCON}$ ) and $1 \mathrm{a}$ (1aCON) from the HCV sequence database, performed using the ClustalW program. Sequences different from consensus are boldface and underlined. Differences in the individual amino acid Core 1a and Core $3 a$ are highlighted. Asterisks at the bottom of a sequence comparison indicate complete identity at that position.

to 1 a Core protein and $98 \%$ similarity to their consensus sequences (Figure 1B). We observed several nucleotide differences in both genotypes when compared with literature. These changes are $\mathrm{N}$ in $1 \mathrm{a}$ at position 4 and $\mathrm{L}$ in $3 \mathrm{a}, \mathrm{Q}$ in 1 and $\mathrm{H}$ in 3 at position $8, \mathrm{~N}$ in $1 \mathrm{I}$ in $3 \mathrm{a}$ at position 16 and $\mathrm{T}$ in $1 \mathrm{a}$ and $\mathrm{N}$ in $3 \mathrm{a}$ at position 70 . The other reported difference is YATG in 1a and FATG in $3 \mathrm{a}$ at position 164 amino acid (Figure 1B). In order to observe whether $1 \mathrm{a}$ and $3 \mathrm{a}$ differentially regulate the expression of Cox-2, iNOS, p-Akt and VEGF, Huh-7 cells were transiently transfected with or without $0.4 \mu \mathrm{g}$ $\mathrm{HCV}$ genotype $1 \mathrm{a}$ and $3 \mathrm{a}$ Core expressing plasmids for $48 \mathrm{hrs}$. The mRNA expression levels of Cox-2, iNOS, and VEGF genes were determined using Real-Time PCR. As shown in Figure 1C, HCV 3a Core induced the expression of Cox-2, iNOS and VEGF genes at significantly higher levels as compared to HCV 1a Core gene. Up-regulated levels for Cox-2, iNOS and VEGF were 4.1, 2.4 and 2.8-fold, respectively, with HCV 3a Core whereas; HCV 1a Core induced Cox-2 (1.3-fold), iNOS 
(1.2-fold) and VEGF (1.3-fold) as compared to control (Figure 2A). Similar results were obtained with $\mathrm{HCV}$ 1a and 3a infected patient's PBMCs. Up-regulation of genes in HCV 3a infected blood was as follow: Cox-2 (4.19-fold), iNOS (3.4-fold), and VEGF (3.22-fold) as compared to HCV 1a infected patient's blood and normal samples (Figure 2B). In HCV 3a infected biopsy samples, the expression levels for these genes were in this fashion: Cox-2 (4.97-fold), iNOS (5.08-fold), and VEGF (6.49-fold) compared with normal samples (Figure 2 C). Cell lysates from Core transfected Huh-7 cells were examined by Western blot analysis using Core, Cox-2, VEGF, and p-Akt specific antibodies. Significant increase $(\mathrm{p}<0.001)$ in the protein expression levels in
$\mathrm{HCV}$ 3a genotype was observed as compared to $\mathrm{HCV}$ 1a (Figure 2D).

In order to determine the effect of HCV Core gene expression on cell proliferation, PGE2 levels were determined by Biotrak Prostaglandin E2 Enzyme Immunoassay system. HCV Core protein of both genotypes significantly increased the production of PGE2 more with HCV 3a Core than HCV 1a in Huh-7 cells (Figure 3A). Core induced cell proliferation was also determined through MTT cell proliferation assay. These results mirrored those observed with PGE2, a significant enhanced cell proliferation observed with both genotypes. HCV 3a genotype has greater effect compared with HCV 1a genotype (Figure 3B). Taken

\section{A)}

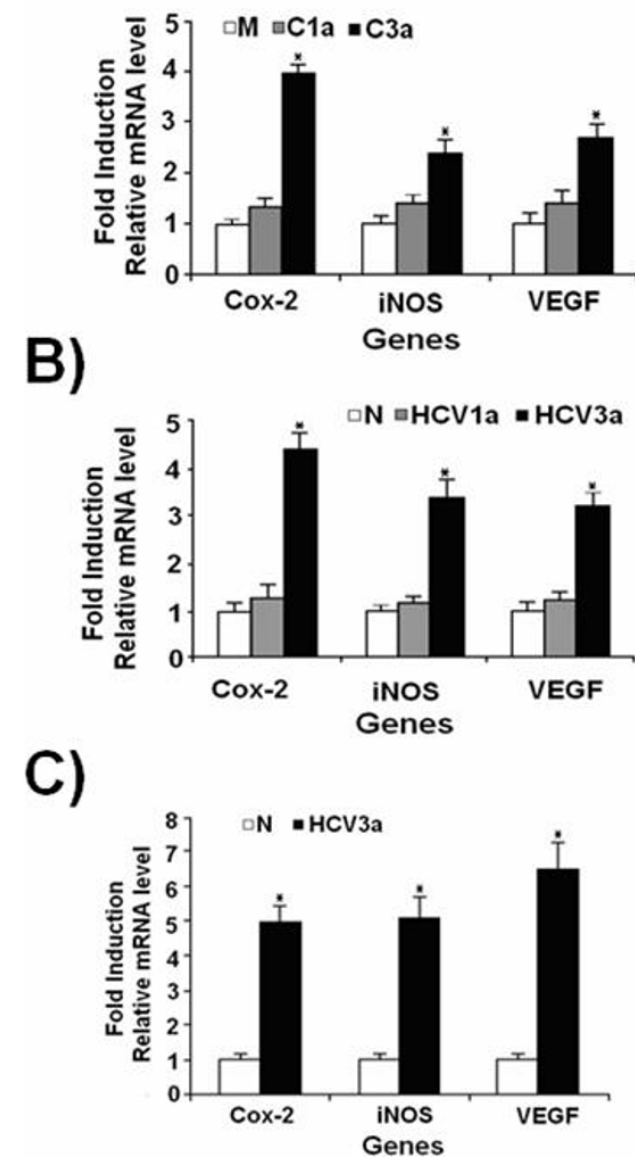

D)
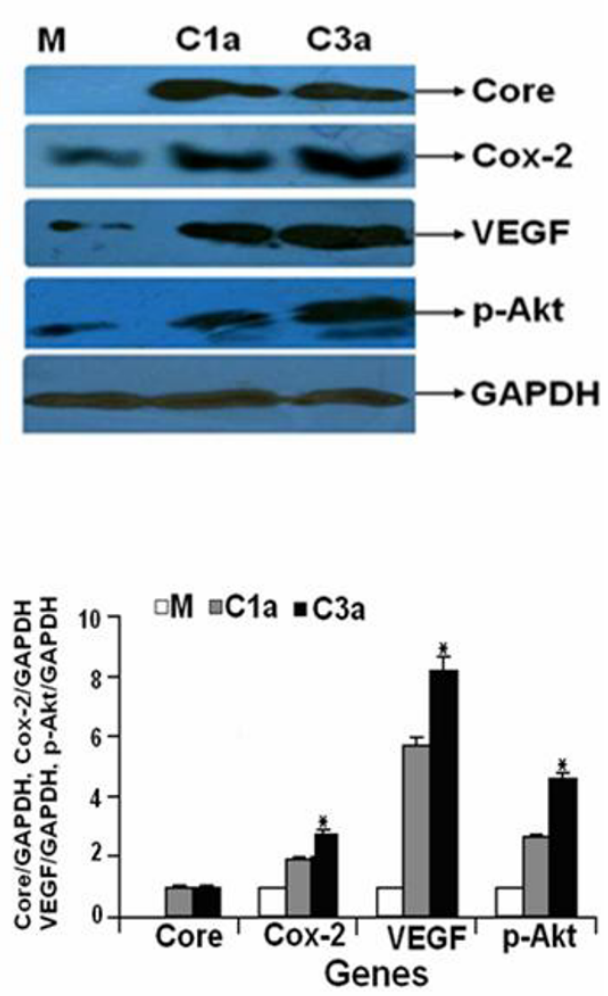

Figure 2 HCV 3a Core gene shows higher induction of Cox-2, iNOS, VEGF and p-Akt compared to HCV 1a Core gene. (A) Comparison of gene expression of Cox-2, iNOS and VEGF in Huh-7 cells transiently transfected with HCV Core 1a (C1a), 3a (C3a) and pCR3.1 plasmid alone as mock (M) samples (0.4 $\mathrm{\mu g}$ DNA/well of each plasmid). After $48 \mathrm{hrs}$ incubation, relative gene expression levels were determined. (B) Comparison of expression of Cox-2, iNOS, and VEGF genes expressed as relative fold induction in HCV 1a and 3a infected patient's blood samples verses normal. (C) Expression of Cox-2, iNOS and VEGF genes in HCV 3a genotype infected liver biopsies verses normal. (D) The protein expression levels were determined by Western blot analysis of Huh-7 cell lysates transfected with HCV Core vectors 1a, 3a and effect on Cox-2, VEGF, p-Akt and GAPDH using specific antibodies. Blots were also normalized by measuring the amount of GAPDH (histogram). Bars are mean of optical density ratio of each group.* $p<0.001$ verses control and Core 1a. GAPDH gene was used as internal control for normalization in Real-Time PCR and in Western blotting. All experiments were performed in 3 independent experiments having triplicate samples in each. 


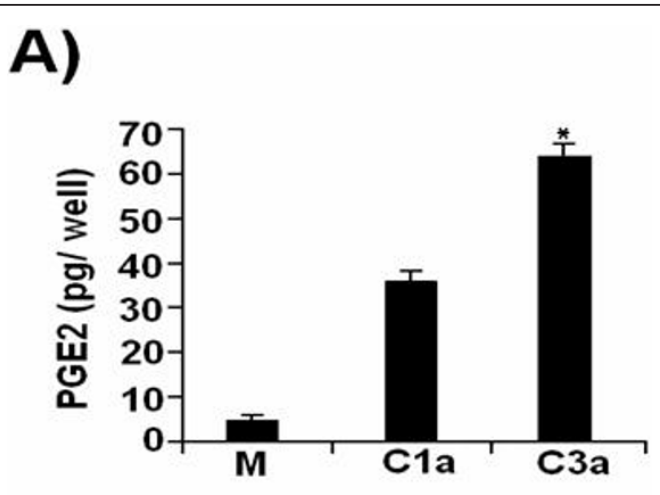

B)

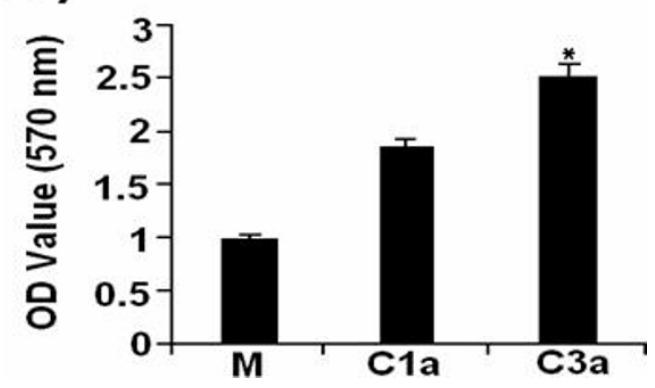

Figure 3 Enhanced expression of PGE2 and cell proliferation in Core transfected Huh-7 cells. (A) Prostaglandin E2 production in response to HCV 1a and 3a Core transfected Huh-7 cells were measured with Biotrak Prostaglandin E2 Enzyme Immunoassay system. (B) MTT assay shows that HCV 3a Core significantly increased the proliferation of Huh-7 cells as compared to mock and Core 1a transfected cells, observed at $570 \mathrm{~nm}$ wavelength. All experiments were performed in 3 independent experiments having triplicate samples in each. Error bars indicate, mean S.D, * $p<0.01$ verses mock.

together, these results show a genome-specific involvement of HCV Core in the induction of Cox-2, iNOS, p-Akt and VEGF host genes at RNA/protein levels in Huh-7 cells. Their high expression in HCV 3a infected patient's samples and cell proliferation assay/PGE2 levels further supported genome-specific role of $\mathrm{HCV}$ in its pathogenesis.

Effect of HCV 3a Core-specific siRNA on the expression of Cox-2, iNOS and VEGF genes

HCV 3a Core showed significantly higher induction levels as compared to HCV 1a Core. Therefore, we utilized gene silencing against $\mathrm{HCV} 3 \mathrm{a}$ Core to investigate its involvement in the regulation of Cox-2, iNOS, p-Akt and VEGF genes. Transient transfection of two in-vitro transcribed siRNAs Csi27 and Csi352 in Huh-7 cells after 48 hrs showed a dramatic reduction of mRNA expression levels of HCV 3a Core gene in a dose-dependent manner. Maximum inhibition of 3 -fold and 2-fold was observed for
Csi27 and Csi352 at $40 \mu \mathrm{M}$ concentrations, respectively, when compared with scramble siRNA (Figure 4A). The effect of HCV 3 a Core siRNAs on mRNA expression levels of Cox-2, iNOS, VEGF genes in Huh-7 cells was also determined. Although, both Csi27 and Csi352 siRNAs decreased the expression levels of all four genes, Csi27 showed dramatic reduction for Cox-2 (2.5-fold) gene, whereas, expression of iNOS, and VEGF was reduced to 1 fold, respectively (Figure 4B). Complementary to reduced mRNA levels, HCV 3a Core protein expression was also inhibited $90 \%$ and $76 \%$ with Csi27 and Csi352 siRNA, respectively. These siRNA also inhibited protein expression levels of Cox-2 (85\% with Csi27 and 70\% with Csi352) and VEGF (75\% with Csi27 and 65\% with Csi352) as compared to control scramble siRNA (Figure 4C). Similarly, the expression of Cox-2 gene was reduced to the basal levels with its own siRNA, whereas, Cox-2 siRNA treatment decreased the expression levels of iNOS and VEGF genes to 2 and 3-fold, respectively (Figure 5A).

\section{Inhibition of genes with combined silencing of HCV 3a} Core and host Cox-2 genes

We further investigated whether HCV Core 3a is regulating gene expression directly or via Cox-2. HCV Core 3a transfected cells were treated with Core and Cox-2 specific or scrambled siRNAs either alone or in combination. Real-Time PCR results showed that Coreinduced expression of Cox-2, iNOS and VEGF genes was markedly reduced to 3,2 and 1.5 fold respectively, after co-treatment with HCV 3 a Core and Cox-2 specific siRNA (Figure 5A). A dramatic reduction was observed at protein levels for Cox-2, VEGF and p-Akt in cells treated with Core and Cox-2 siRNA in combination (Figure $5 \mathrm{~B}$ ). The over all mechanism of regulation of oxidative stress by HCV Core and Cox- 2 has been shown in Figure 6.

\section{Suppression of viral load and gene expression by HCV Core and Cox-2 siRNA in Huh-7 cells}

Additionally, the efficacy of siRNA against HCV 3a Core and Cox- 2 genes alone or in combination was evaluated in serum-infected Huh-7 cells. A remarkable suppression of HCV RNA was observed up to $92 \%$ with $\mathrm{HCV}$ 3a Core-siRNA, 83\% with Cox-2 siRNA and 95\% with combination of both siRNAs (Figure 7A). Both siRNA either alone or in combination inhibited the RNA expression levels of Cox-2, iNOS and VEGF. These results indicate that siRNA against $\mathrm{HCV}$ 3a Core and Cox-2 genes decreased the mRNA expression levels of Cox-2 (2-fold), iNOS (1.5-fold) and VEGF (1.8-fold) genes (Figure 7B). Additionally, there was significant reduction at protein levels of Cox-2, VEGF and p-Akt in cells treated with Core and Cox-2 siRNA (Figure 7C). 

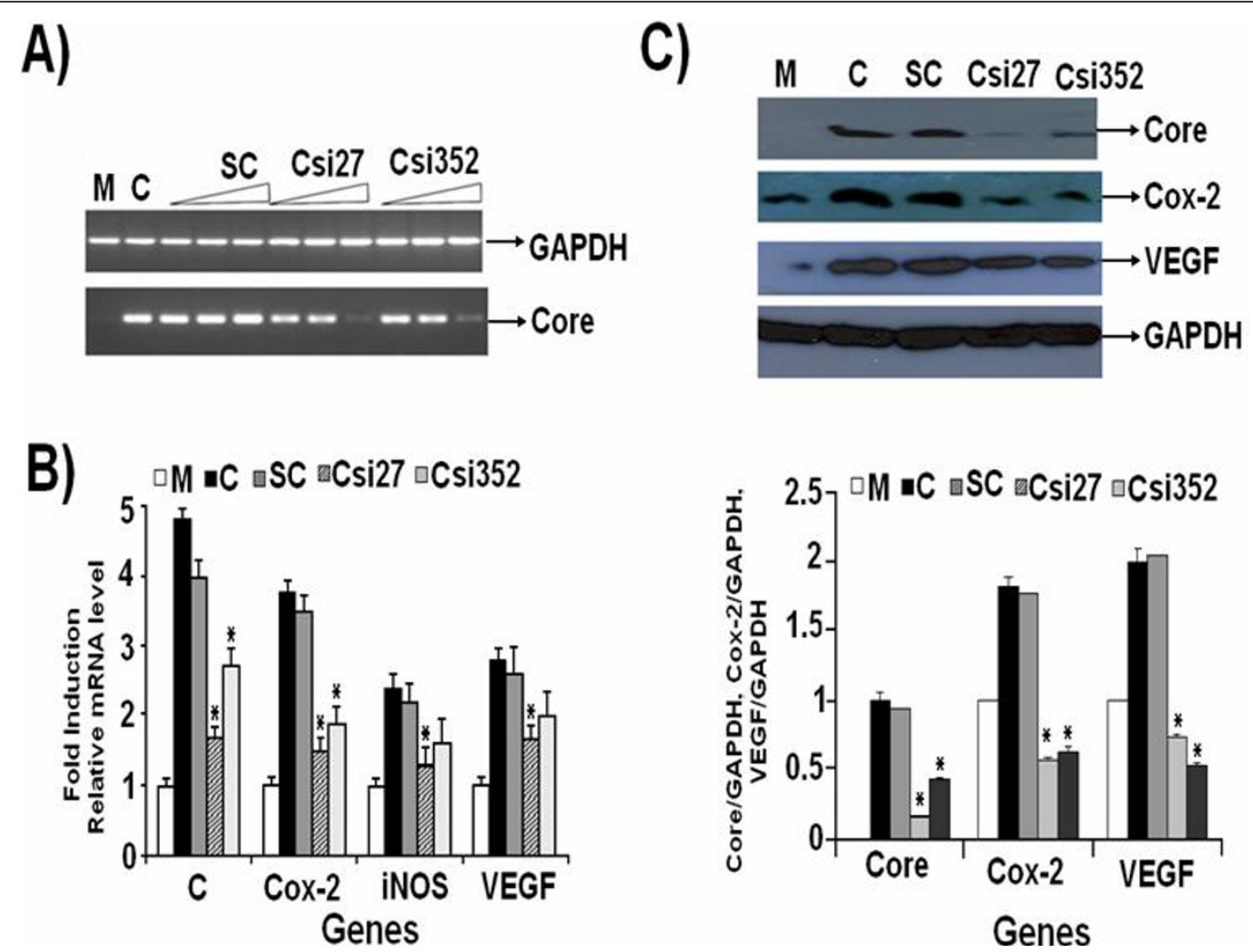

Figure 4 HCV 3a Core-specific siRNA inhibit expression of genes involved in HCV pathogenesis. Huh-7 cells were transfected with HCV $3 a$ Core expression vector or mock along with or without siRNA. (A) Dose dependent mRNA expression of HCV 3a Core gene as a result of $10 \mu \mathrm{M}$, $20 \mu \mathrm{M}$ and $40 \mu \mathrm{M}$ of siRNAs for $48 \mathrm{hrs}$. Cells were harvested and relative RNA levels in PCR Csi27 and Csi352 siRNAs tranfected cells were determined using semi-quantitative PCR. Expression levels for mock-transfected (M), HCV 3a Core expression plasmid (C), scramble siRNA (SC) and GAPDH are also shown. (B) Silencing effect of HCV 3a Core gene on the RNA expression levels of cellular genes (Cox-2, iNOS and VEGF) 48 hrs post transfection on Real-Time PCR using gene specific primers in comparison to mock was performed. GAPDH was used as internal control. Three independent experiments were performed having triplicate samples. Error bars indicate, mean S.D, ${ }^{*} p<0.001$ verses Core. (C) Silencing of HCV 3a Core gene and its effect on Cox-2 and VEGF protein level using specific antibodies were determined by Western blot analysis after 48 hrs transfection in Huh-7 cells with GAPDH as internal control. Bars are mean of optical density ratio of each group.* $p<0.001$ verses control and Core $3 a$.

\section{Discussion}

$\mathrm{HCV}$-induced pathogenesis like liver injury, insulin resistance and steatosis may be genotype specific. A high rate of $\mathrm{HCV}$ associated HCC prevalence in Asia has been observed with genotype 3 followed by 1 responsible for most of the cases in Pakistan [3,18-20]. Several studies have been conducted to unravel the HCV pathogenesis related to genotype 1 and $2[20,21]$. However, no studies related to role of $\mathrm{HCV}$ genotype $3 \mathrm{a}$ in oxidative stress are currently available. In this study, we compared the expression of HCV genotype 1a and $3 \mathrm{a}$ in oxidative stress.

Our results showed a significantly higher expression of Cox-2, iNOS, and VEGF genes in HCV 3a patient blood as compared with HCV 1a genotype at mRNA levels. We observed the significant stimulation of Cox-2, iNOS, and VEGF in HCV 3 a infected patients biopsy samples compared to normal. Unfortunately, we were unable to compare the expression level of these genes in $\mathrm{HCV}$ infected 1a patients biopsy samples because of nonavailability of 1 a liver biopsy samples as very few patients agreed to underwent liver biopsy. The expression levels of Cox-2, iNOS, p-Akt and VEGF are positively correlated in cultured cells and in human liver cancer tissues suggesting their involvement in chronic liver diseases. NO and Cox-2 have carcinogenic effects achieved either directly or by producing mediators that regulate cellular growth $[9,10]$. Over expression of Cox2 induces angiogenesis through increased levels of proinflammatory molecule PGE2 which in return activates VEGF [22] and Akt that promote the growth of human HCC cells $[9,13]$.

$\mathrm{HCV}$ Core protein is involved in a whole array of host cell functions including signal transduction and 


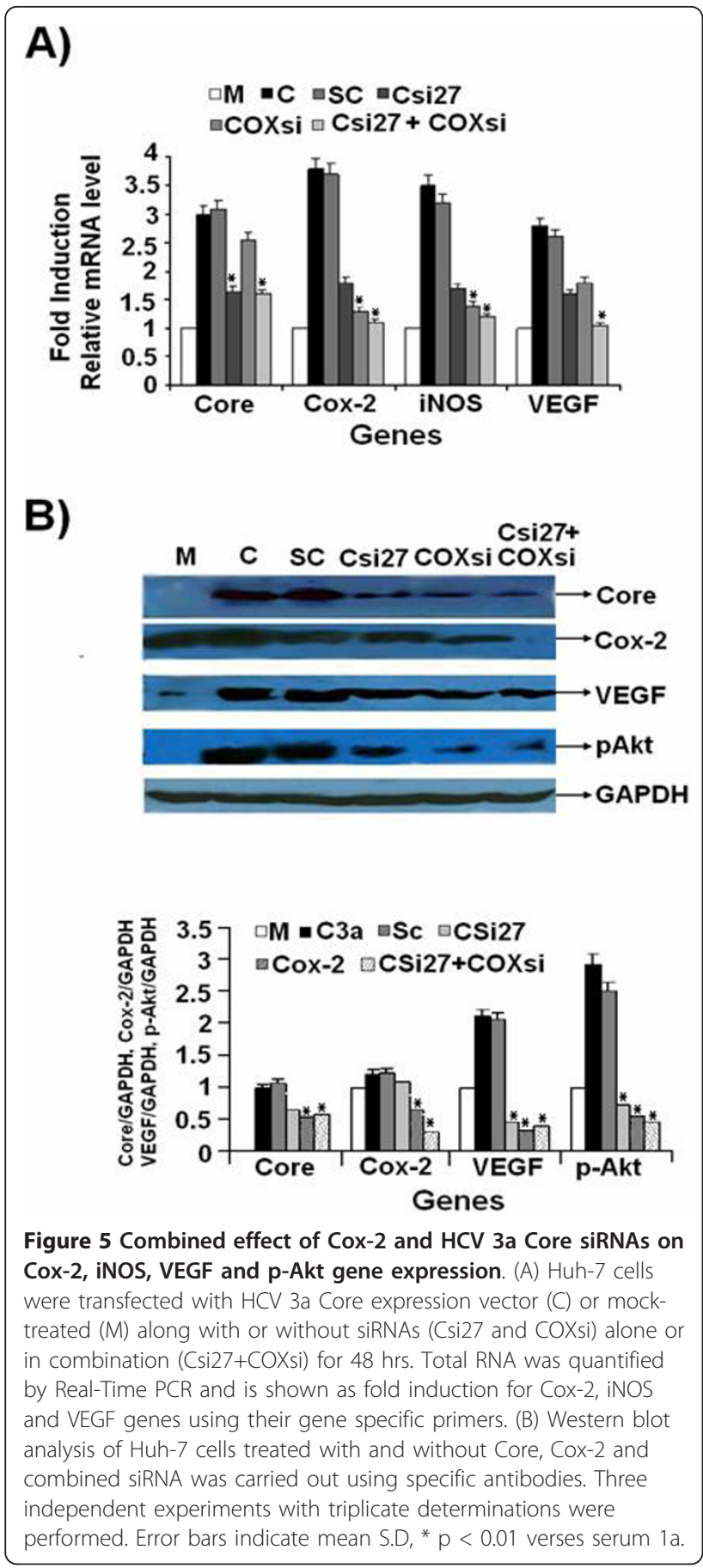

transcriptional regulation of genes in the liver (5). It is reported that HCV Core protein regulates Cox-2 expression in hepatocytes and causes oxidative stress leading to $\mathrm{HCC}$ [7]. In the present study, Core protein of $\mathrm{HCV}$ 3a was found to enhance the expression of cellular genes Cox-2, iNOS, p-Akt and VEGF at mRNA and protein at higher level compared to Core gene of $\mathrm{HCV}$ $1 \mathrm{a}$ in Huh-7 cell line. The production of PGE2 was

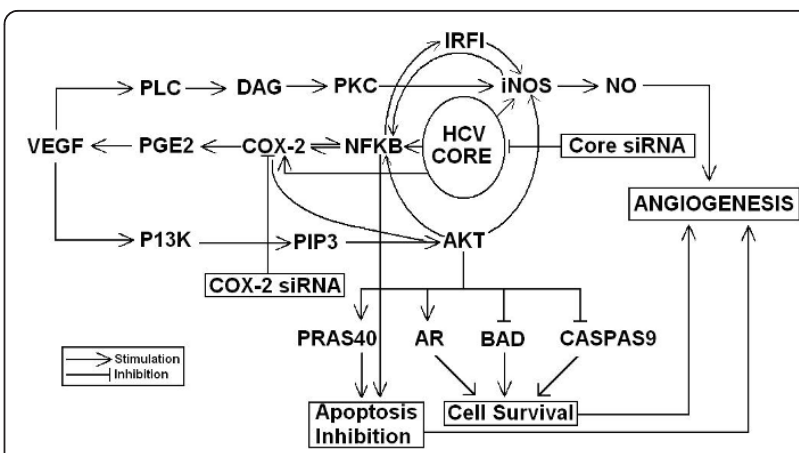

Figure 6 HCV Core protein affects on the cellular genes involved in oxidative stress, apoptosis, cell survival and angiogenesis. Schematic diagram illustrating the role of HCV Core on cellular genes. In HCV, normal angiogenesis process can be malignant by deregulation of genes involved in this pathway. HCV Core protein up-regulates NFKB, which further up-regulates iNOS and COX-2 pathways, and inhibit apoptosis by blocking bad and caspase pathway. COX-2 up-regulation leads to apoptosis inhibition via VEGF pathway. VEGF can trigger angiogenesis either by iNOS or AKT activation. AKT singling also up-regulates AR and inhibit BAD and Caspase9 that leads to angiogenesis via cell survival. AKT also have direct impact on iNOS regulation that also escorts to angiogenesis. We corroborated that using siRNA against Core, or Cox-2 either alone or in combination can block angiogenesis directly or via Cox-2 reduced expression. PLC, PhosphoLipase; DAG, diacylglycerol; PKC, protein kinase C; iNOS, inducible nitric oxide synthase; NO, nitric oxide; VEGF, vascular endothelial growth factor; PGE2, prostaglandin E2; COX-2, cyclooxygenase-2; NFKB, nuclear factor kappa-B; P13K, phosphoinositide-3-kinase; PIP3,

phosphatidylinositol 3,4,5-trisphosphate; PRAS40, proline-rich Akt substrate of $40 \mathrm{kDa}$; $\mathrm{AR}$, Aldose reductase; BAD, Bcl-XL/Bcl-2-

associated death promoter; CASPASE9, apoptosis-related cysteine peptidase.

assayed in HCV 1a and 3a transfected cells and results indicated that the level of PGE2 was increased in HCV 3a Core transfected cells as compared to 1a. Furthermore, cell proliferation was found to be enhanced in Core 3a transfected cells because of Core-induced Cox2 activation of PGE2 release at $48 \mathrm{hrs}$ post transfection (Figure 3). Our results support the observation that enhanced synthesis of Cox-2 as a consequence of Core 3a induced PGE2 that stimulates the release of proangiogenic factor VEGF. VEGF production is regulated by COX-2, suggesting a promoting role of COX-2 in tumor angiogenesis through the COX-2/VEGF system [[20,23] and [24]].

Many studies have reported that substitutions in the HCV Core region results in enhanced insulin resistance, steatosis, oxidative stress and hepatocellular carcinoma $[25,26]$. Amino acid substitution at the sequence YATG (1b) and FATG (3a) of HCV Core gene was found to be important for FAS activation in genome specific manner [21]. Previously, Hourioux et al., (2007) showed a greater involvement of these $\mathrm{HCV} 3 \mathrm{a}$ amino acid 


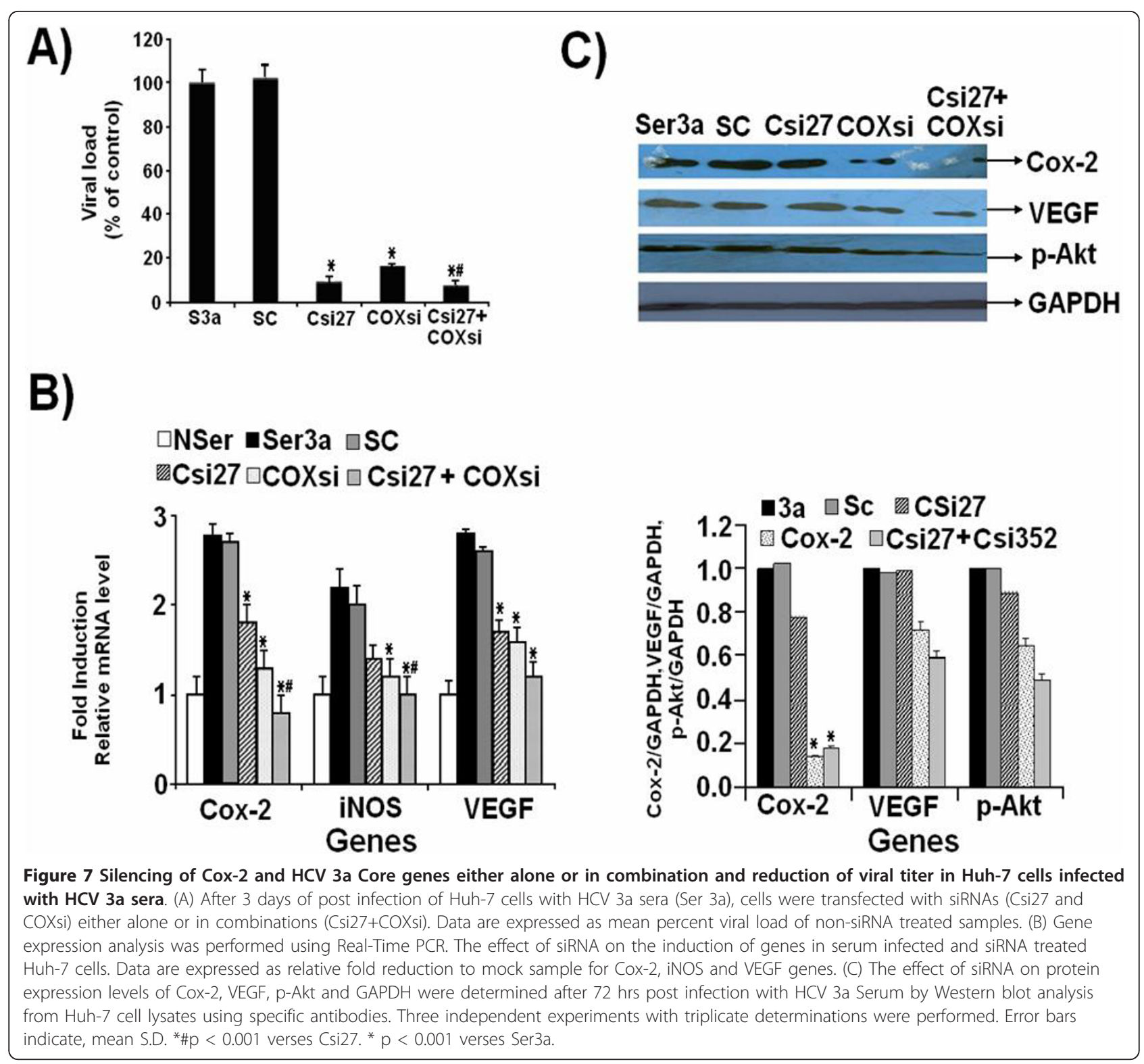

sequences in lipid accumulation and steatosis in cell culture system [27]. Furthermore, Jhaveri et al., (2008) reported that amino acid substitution of $\mathrm{HCV}$ 3a Core (LLSCLIH) at 182 and 186 positions are associated with $\mathrm{H} \bar{C} \mathrm{~V}$ induced steatosis [28]. Amino acid substitution in HCV Core gene has different impact in hepatic steatosis and oxidative stress in chornic HCV patients. Tachi et al (2009) has reported that in HCV genotype 1b infected patients with hepatic steatosis, there was amino acid substitution ' $Q$ ' at 70 while in patients without steatosis Arg was present. He also reported that Met91aa of Core region in patients infected with HCV $1 \mathrm{~b}$ have high oxidative stress measured through the level of 8-hydroxy20-deoxyguanosine as compared in those with Leu91aa [20]. Mann et al., observed that the divergence in Core
9-11 amino acid at genotype level modulate the NF-kB activation, a transcription factor which play important factor in inflammation and liver injury. Core encoding RKP failed to activate NF-kB signaling in vitro while NF-kB activation by Core encoding RQT does not differ from control RKT Core [29]. Steatosis and oxidative stress are interlinked and arise due to accumulation of triglyceride rich lipids in cytoplasm [4,30]. We have also observed the same amino acid variations that were previously reported plus few other substitutions in HCV 3a Core sequence in comparison with 1a (Figure 1B). Although there is $90 \%$ amino acid sequence similarity, however, we observed few sequence differences too. These changes are $\mathrm{N}$ in $1 \mathrm{a}$ at position 4 and $\mathrm{L}$ in $3 \mathrm{a}, \mathrm{Q}$ in 1 and $\mathrm{H}$ in 3 at position $8, \mathrm{~N}$ in $1 \mathrm{I}$ in $3 \mathrm{a}$ at position 
16 and $\mathrm{T}$ in $1 \mathrm{a}$ and $\mathrm{N}$ in $3 \mathrm{a}$ at position 70 . Therefore, we speculate that these sequences may play a role in differentially regulating genes involved in oxidative stress leading to HCC. Vidali et al., found a relationship between oxidative and hepatic steatosis in the progression of chronic hepatitis C [16]. Several recent studies have shown variable responses for interferon IFN-ribavirin combination therapy, oxidative stress/steatosis and insulin resistance due to the amino acid substitutions in the HCV Core region [26,31-33]. Since, there is no previous report linking amino acid variations to oxidative stress in a genome-specific manner, additional studies are needed to identify the contribution of these substitutions to the $\mathrm{HCV}$ induced pathogenesis.

We silenced Core gene using siRNA to further confirm the role of $\mathrm{HCV}$ 3a Core gene in $\mathrm{HCV}$ infection and stimulation of cellular genes. RNAi activity directed against multiple target sequences of the HCV genome has been found to block effectively the synthesis of replicon RNA [17,34]. We observed efficient inhibition of HCV Core by siRNA against this functionally important region of $\mathrm{HCV} 3 \mathrm{a}$ genotype. Protein expression analysis revealed suppression of $\mathrm{HCV}$ Core protein levels by $90 \%$ in Csi27, while suppression by Csi352 siRNA was $76 \%$ (Figure 4). Two different groups have used siRNA against Core gene of $\mathrm{HCV} 1 \mathrm{a}$ and $1 \mathrm{~b}$ genotype and observed $60 \%$ and $80 \%$ reduction in mRNA and protein expression, respectively $[34,35]$. Silencing of $\mathrm{HCV}$ Core through Core specific siRNA resulted in reduced expression of host cellular genes Cox-2, iNOS and VEGF in Core transfected Huh-7 cells at both mRNA and protein levels. The significant inhibition of Core mRNA in siRNA transfected cells also resulted in $50 \%$ reduction in PGE2 production and cell proliferation. The ability of Core siRNAs to inhibit HCV expression correlates well with the established role of $\mathrm{HCV} 3 \mathrm{a}$ Core gene in oxidative stress and angiogenesis by regulating these genes.

HCV Core up-regulate Cox-2 levels that correlated with genes involved in $\mathrm{HCV}$ pathogenesis. Since the inhibitors of Cox-2, such as siRNAs and celecoxib showed an inhibition of cell proliferation and carcinogenesis, we used Cox-2 specific siRNA to determine its effect on gene expression. Cox-2 specific siRNA (COXsi) significantly decreased the expression of not only the Cox-2 itself but also the expression levels of pAkt, iNOS and VEGF. These results suggest that Cox-2 pathway is involved in mediating the activation of $\mathrm{p}$ Akt, iNOS and VEGF in HCV Core expressing cells (Additional file 1 and Additional file 2, Figure S1).

Additionally, we explored whether HCV Core induced Cox-2 gene, which in turn activated Akt (phosphrylation), iNOS, and VEGF or it has a direct role in activating cellular genes understudy. We observed significant reduction in the expression of Core and these genes when treated with Csi27 and COXsi in combination at both mRNA and protein levels (Figure 5). The significant inhibition of Core and Cox-2 mRNA in siRNA transfected cells either alone or in combination also resulted in reduced PGE2 production and cell proliferation to $50 \%, 65 \%$ and $85 \%$, respectively (Additional file 1 and Additional file 3, Figure S2). The reduction of these genes by both HCV Core and Cox-2 siRNA indicate that $\mathrm{HCV}$ Core is involved in $\mathrm{HCV}$ pathogenesis not only by exerting its effect through Cox-2 signaling but is also directly involved in the regulation of gene expression. Zhao et al., (2007) observed reduced production of PGE2 and VEGF level in treated Huh-7 cells, and suppressed $\mathrm{HCC}$-associated angiogenesis in vitro and in vivo using Cox-2 siRNA [20].

Most of the studies are conducted in Huh-7 derived cell lines and with replicons supporting HCV RNA transcription and protein synthesis. Recently, different groups have studied the HCV replication in serum infected liver cell lines [17,36-39]. In order to confirm above results, we infected Huh-7 cells with native viral particles from HCV genotype 3 a positive serum, the most prevalent type in Pakistan using already established protocol $[37,40]$. Previously in our laboratory, Khaliq et al., 2010 infected Huh-7, HEK, MDBK and HeLa cell line with $\mathrm{HCV} 3 \mathrm{a}$ infected serum and observed that MDBK and HeLa cell lines did not support HCV infection [41].

The current therapies against HCV have limited efficacy due to the development of viral resistance and HCV high mutation rate. The problem of viral mutants could be resolved by using a mixture of siRNAs against different sequences. Several studies have also demonstrated the feasibility of targeting host cellular and viral factors involved in $\mathrm{HCV}$ infection as potential targets for therapy either alone or in combinations of both like Lamin A/C, Caspase-8, Hsp90 and HCV genes [42-47]. The effect of HCV sera on the expression of Cox-2, iNOS and VEGF genes and their inhibition by siRNA against $\mathrm{HCV}$ Core and host gene Cox-2 was also observed. The expression of Cox-2, iNOS and VEGF genes both at mRNA and protein levels were found to be more stimulated in Huh-7 cells infected with $\mathrm{HCV}$ 3a serum as compared to HCV 1a (Data shown in Additional file 1 and Additional file 4, Figure S3). These results were consistent with our HCV Core over-expression studies. We observed HCV replication in the Huh7 cells through detection of 5'UTR by Real-Time PCR in cells at $3^{\text {rd }}$ and $5^{\text {th }}$ day post-infection and $92 \%$ reduction with Csi27, 83\% with COXsi and 95\% inhibition when both siRNAs were used (Figure 7 ). At the day $3^{\text {rd }}$ post infection, we observed that the decline of viral titer using Core and Cox-2 siRNA in liver cells also reduced 
the expression of Cox-2, pAkt, iNOS and VEGF. Zekri et al., has reported that siRNA against HCV Core and 5'UTR effectively blocked HCV replication in serum infected Huh-7 cells [40]. Many authors have observed and also correlated amino acid substitution in Core in HCV infected patient's samples with steatosis, interferon response, insulin resistance and oxidative stress. $\mathrm{HCV}$ structural proteins play a direct role in the development of liver steatosis and increase the risk of liver cancer in transgenic mice [48-50]. In transgenic mouse model, expressing HCV structural proteins produced profound liver damage leading to hepatocellular carcinoma. Moriya et al., (1997) reported that transgenic mouse model expressing HCV Core protein showed hepatic tumor, lipid accumulation in 16 months old mice [51]. Transgenic mice with steatosis displayed dysplastic growth of cells evolving into tumor formation. Furthermore, transgenic mice showed deposition of collagen and progressive fibrosis [52]. In our study, we observed high expression of oxidative stress related genes in patients infected with $\mathrm{HCV}$ genotype $3 \mathrm{a}$ as compared to $1 \mathrm{a}$. In future, the correlation of amino acid substitutions are need to be address in transgenic mouse model or the other natural victim of HCV that is chimpanzee to confirm our results and the full understanding of the pathogenesis.

\section{Conclusions}

In conclusion, these studies for the first time suggest an interaction of $\mathrm{HCV}$ 3a Core and Cox-2 in regulating the genes involved in $\mathrm{HCV}$ pathogenesis which may provide a better understanding for genome-specific mechanisms involved in disease progression regulating Cox-2, pAkt, iNOS, PGE2 and VEGF expression directly or indirectly. Another outcome of these studies is the viral titer reduction observed with combined gene silencing of HCV Core and Cox-2, which support the idea of dual strategy against both the viral and host genes to be a potent approach in the treatment of chronic hepatitis $\mathrm{C}$.

\section{Methods}

\section{Patient's Samples}

The local HCV 3a and 1a patient's serum samples used in this investigation were collected from CAMB (Center for Applied Molecular Biology) Diagnostic Laboratory, Lahore, Pakistan after clinical diagnosis. ELISA and PCR positive samples were stored at $-80^{\circ} \mathrm{C}$ prior to RNA extraction. The genotyping and quantification was performed as previously described by Ahmad et al., (2010) [3]. None of the subjects had received antiviral therapy. Subjects with clinical evidence of HBV, diabetes and any other type of cancer were excluded from study. The subject population with chronic HCV infection, viral load > $2 \times 10^{8} \mathrm{IU} / \mathrm{ml}$ of genotype $1 \mathrm{a}$ and $3 \mathrm{a}$ were included in this study. Blood samples from three control and six HCV positive patients for viral serum inoculations were taken and immediately stored at $-20^{\circ} \mathrm{C}$. For expression of oxidative stress related genes, three normal and six HCV positive liver biopsies and their blood samples were also collected from Jinnah Hospital Lahore, Pakistan. Study was approved from the Institutional Ethical Committee and patient's written consent was obtained.

\section{RNA Isolation from Blood and Biopsy Samples}

Total RNA from liver biopsies was extracted by using Qiagen RNeasy Mini kit (Qiagen, USA). For PBMCs, TRIzol reagent (Invitrogen, Carlsbad, CA) was used according to manufacturer's protocol. Briefly, first the white blood cells (PBMC) were separated from blood collected in anticoagulant (EDTA) tube. For the lysis of erythrocytes $900 \mu \mathrm{l}$ of RBC lysis solution (Gentra USA) was added in $300 \mu \mathrm{l}$ of whole blood. The resulting mixture was incubated at room temperature for 10 minutes and then, centrifuged at $1000 \mathrm{rpm}$ for 1 minute at $4^{\circ} \mathrm{C}$. The same step was repeated unless PBMC formed a tight white pellet at the bottom of the tube. Then Trizol reagent (Invitrogen, Carlsbad, CA) was used for the isolation of RNA from these cells according to manufacturer's protocol.

\section{Plasmid Construction}

Viral RNA was isolated from thawed $100 \mu \mathrm{l}$ serum aliquots using Gentra RNA isolation kit (Gentra System Pennsylvania, USA) according to the manufacturer's instructions. 100-200 ng extracted viral RNA was used for RT PCR using the SuperScript III one step RT-PCR system (Invitrogen). HCV complementary DNA (cDNA) encoding the full length Core protein (amino acid 1-191 of $\mathrm{HCV}$ isolates of $\mathrm{HCV} 3 \mathrm{a}$ genotype) were amplified using Core specific primers. The PCR conditions were $94^{\circ} \mathrm{C} 3 \mathrm{~min} ; 94^{\circ} \mathrm{C} 35 \mathrm{sec} ; 58^{\circ} \mathrm{C} 45 \mathrm{sec} ; 72^{\circ} \mathrm{C} 1 \mathrm{~min}$ for 35 cycles and final extension at $72^{\circ} \mathrm{C}$ for $10 \mathrm{~min}$. PCR product was cloned into pCR3.1 mammalian expression plasmid with FLAG tag inserted at the 5 ' end with restriction sites EcoRV and Xba1 (Fermentas, USA). Similarly, The plasmid HFL (a kind gift provided by Dr. Zafar Nawaz University of Miami, USA) containing full length of HCV 1a was used as the template for PCR and later cloning of HCV 1a Core in pCR3.1 mammalian expression vector (Figure 1A). Sequencing was performed for both expression plasmids by DNA Core facility at CAMB, Lahore, Pakistan. Accession number for HCV 3a Core sequences submitted to NCBI is EU266536.

\section{Cell Culture}

Huh-7 cell line (kindly provided by Dr. Zafar Nawaz, University of Miami, USA) was maintained in $75 \mathrm{~cm}^{2}$ culture flasks (Iwaki, Japan) containing DMEM (Sigma Aldrich, USA) supplemented with $100 \mu \mathrm{g} / \mathrm{ml}$ penicillin/ 
streptomycin, and 10\% FBS as complete culture media (CCM) (Sigma Aldrich, USA), at $37^{\circ} \mathrm{C}$ with $5 \% \mathrm{CO}_{2}$. The CCM was renewed every $3^{\text {rd }}$ day and cells were passaged every 4-5 days. Viable cells were counted using 0.5\% trypan blue (Sigma Aldrich, USA).

\section{Transient Transfection}

Approximately $5 \times 10^{5} \mathrm{Huh}-7$ cells were seeded into 6well tissue culture plates, at $24 \mathrm{hrs}$ prior to transfection. Huh-7 cells were transiently transfected with and without expression plasmids $(0.4 \mu \mathrm{g})$ of HCV Core $1 \mathrm{a}$ and 3a genotype in serum-free media using Lipofectamine ${ }^{\mathrm{TM}}$ 2000 (Invitrogen) according to the manufacturer's protocol. After 6 hours incubation at $37^{\circ} \mathrm{C}$ in $5 \% \mathrm{CO}_{2}$, cells were washed with $1 \times$ PBS and CCM was added to the cells. Cells were harvested at $48 \mathrm{hrs}$ post-transfection for genes expression analysis by Real-Time PCR and western blot analysis.

\section{Design and Synthesis of siRNA}

The DNA sequencing facility at CAMB Lahore, Pakistan carried out sequencing of the Core gene of local HCV 3a patient's from serum samples. These sequences were aligned using the software CLUSTAL_W option of MEGA v.3.1. siRNA against HCV 3a Core and Cox-2 were designed to the most conserved target region using the Ambion's siRNA design tool http://www.ambion. com/techlib/misc/siRNA_tools.html (Table 1) and did not show any homology to other known human genes. A negative control siRNA (scrambled siRNA) was designed using scrambled sequences (Table 1). siRNA were synthesized using Ambion's siRNA silencer kit according to the manufacturer's instructions (Ambion, USA).

\section{Viral Inoculation}

Huh-7 cell line was used to establish the in vitro replication of HCV. Cell culturing and viral inoculations were conducted as published previously $[37,40]$. High viral titer $\left(>1 \times 10^{8} \mathrm{IU} / \mathrm{ml}\right)$ from HCV $3 \mathrm{a}$ and 1a patient's was used as principle inoculums in these experiments. Huh7 cells were maintained in 6 -well culture plates, as described above, to semi-confluence in CCM, washed twice with serum-free medium, then inoculated with $500 \mu \mathrm{l}\left(5 \times 10^{7} \mathrm{IU} /\right.$ well $)$ of HCV $3 \mathrm{a}$ and $1 \mathrm{a}$ infected patient sera and $400 \mu \mathrm{l}$ serum free media. Cells were maintained overnight at $37^{\circ} \mathrm{C}$ in $5 \% \mathrm{CO}_{2}$. The next day, adherent cells were washed three times with $1 \times$ PBS, the CCM was added and incubation was continued for another 48 hrs. Cells were harvested and viral RNA in Huh-7 cells assessed qualitatively by Real-Time PCR.

\section{RNA Interference}

To examine the effects of HCV Core and Cox-2 genes on cellular gene expression, cells were transfected with
Table 1 Sequences of primers and target siRNAs

\begin{tabular}{ll}
\hline Primers used in vector construction \\
\hline Core3a-sense & ATGAGCACACTTCCTAAACC \\
Core3a-antisense & CATGGCTGCTGGATGAATTA \\
3aCore-sense & GCGATATCATGAGCACACTTCCTAAA \\
3aCore-antisense & AATCTAGATCATGGCTGCTGGATGAAT \\
1aCore-sense & GCGATATCAGCACGAATCCTAAAGGT \\
1aCore-antisense & AATCTAGATTAGG CTGAAGCGGGACGGT \\
\hline Primers used in Real-Time PCR \\
\hline RTp3.1-sense & GGACGACGATGACAAGGACT \\
RT1a-antisense & GGGGAGACAGGA GCCATC \\
RT3a-antisense & GGCTGTGACCGTTCAGAAGT \\
Cox-2-sense & AACCCACTCCAAACACAG \\
Cox-2-antisense & CTGGCCCTCGCTATGATCT \\
iNOS-sense & CACCTTGGAGTCACCCAGT \\
iNOS-antisense & ACCA CTCGTACTTGGATGC \\
VEGF-sense & CTTGCCTGCTGCTCTACC \\
VEGF-antisense & CACACAGGATGGCTTGAAG \\
\hline GAPDH-sense & ACCACAGTCCATGCCATCAC \\
GAPDH-antisense & TCCACCACCCTGTTGCTGTA \\
\hline siRnAs used for silencing \\
\hline Csi27-sense & AAGGATGGTGTTCTTTGGTCCTGTCTC \\
Csi27-antisense & AAACCAAAAGAACACCATCCCCTGTCTC \\
Csi352-sense & AAATCGATGACTTACCCAAACCTGTCTC \\
Csi352-antisense & AATTGGGTAAAGCATCGATCCTGTCTC \\
Scramble-sense & AAGTCGAGTCGCGTATGCAGGCCTGTCTC \\
Scramble-antisense & AACCTGCATACGCGACTCGACCCTGTCTC \\
COXsi-sense & AATTATTTCTGAAACCCACTCCCTGTCTC \\
\hline & AAGAGTGGGTTTCAGAAATAACCTGTCTC \\
\hline
\end{tabular}

Core and Cox-2 specific or scrambled siRNAs. Briefly, cells were seeded in 6 -well $\left(5 \times 10^{5} /\right.$ well $)$ plates and cultured in CCM until they became $60-80 \%$ confluent. Cells were transiently transfected with $10,20,40 \mu \mathrm{M} /$ well of specific siRNAs (Csi27, Csi352 and COXsi either alone or in combination) or scrambled siRNA along with $0.4 \mu \mathrm{g}$ of HCV Core $3 \mathrm{a}$ in serum free media using Lipofectamine 2000 (Invitrogen) according to the manufacturer's protocol. After $6 \mathrm{hrs}$ incubation at $37^{\circ} \mathrm{C}$ in $5 \% \mathrm{CO}_{2}$, CCM was added to the cells. Cells were then harvested for gene expression and protein analysis after 48 hrs. Protein analysis was carried out for above mentioned experiments in 6-well plates.

For HCV infected experiments, Huh-7 cells were seeded in 6-well plates as described above and cells were infected with $\mathrm{HCV}$ infected serum (see Viral Inoculum section for details). To analyze the effect of siRNA on HCV infection, serum-infected Huh-7 cells were seeded after three days of infection in 6 well plates and grown to $80 \%$ confluence with $2 \mathrm{ml}$ of standard medium. This was followed by transfection of infected cells with or without $40 \mu \mathrm{M} /$ well of Csi27 and COXsi siRNA either alone or in combination. Cells were 
harvested and analyzed for gene expression analysis by Real-Time PCR and viral load determination as described below.

\section{Cell Proliferation Assay and PGE2 Measurements}

Approximately $2 \times 10^{3}$ Huh-7 cells were seeded into 96well tissue culture plates for $24 \mathrm{hrs}$ prior to transfection. Huh-7 cells were transiently transfected with 0.1 $\mu \mathrm{g} /$ well of HCV Core 1a and 3a plasmids with and without Core and Cox-2 siRNA in serum-free media using Lipofectamine ${ }^{\mathrm{TM}} 2000$ (Invitrogen) according to the manufacturer's protocol. After $6 \mathrm{hrs}$ incubation at $37^{\circ} \mathrm{C}$ in $5 \% \mathrm{CO}_{2}, \mathrm{CCM}$ was added to the cells. The MTT colorimetric assay was performed to detect cell proliferation after $24 \mathrm{hrs}$ and $48 \mathrm{hrs}$ of incubation. The absorbance of resulting formazan crystals (solubilized with DMSO) was read at $590 \mathrm{~nm}$ on ELISA plate reader. PGE2 levels were also determined in Huh-7 cells using above cell culture/transfection conditions and assayed with the Biotrak Prostaglandin E2 Enzyme Immunoassay system (Amersham Pharmacia Biotech, USA) according to the manufacturer's protocol at 459 $\mathrm{nm}$ wavelength.

\section{Viral Load}

Viral RNA was isolated using Gentra RNA isolation kit (Gentra System Pennsylvania, USA) according to the manufacturer's instructions. For viral quantification Sacace HCV quantitative analysis kit (Sacace Biotechnologies Caserta, Italy) was used. Briefly, $10 \mu \mathrm{l}$ of extracted viral RNA was mixed with an internal control derived from 5'UTR provided by Sacace HCV Real TM Quant kit and subjected to viral quantification using Real-Time PCR Smart Cycler II system (Cepheid Sunnyvale, USA). For protein expression analysis at day $3^{\text {rd }}$ of viral inoculation, cells were washed 3 times before harvesting and Western blotting was performed.

\section{Real-Time PCR}

For gene expression analysis, total RNA from Huh-7 cells transiently transfected with mock, HCV Core 1a and 3a was extracted using TRIzol Reagent (Invitrogen, USA). cDNA was synthesized using $1 \mu \mathrm{g}$ of total RNA with SuperScript III Kit (Invitrogen, USA). Gene expression analysis was carried out using Real Time PCR ABI 7500 system (Applied Biosystems Inc, USA) with SYBR Green mix (Fermentas, Canada) using gene specific primers (see Table 1). PCR conditions were as follow: $95^{\circ} \mathrm{C}, 30 \mathrm{sec} ; 58^{\circ} \mathrm{C}, 30 \mathrm{sec}$ and extension at $72^{\circ} \mathrm{C}$ for $45 \mathrm{sec}, 40$ cycles. The relative gene expression analysis was carried out using the "SDS 3.1 software" (provided by Applied Biosystems Inc, USA). GAPDH was used as internal control for normalization.

\section{Western Blotting}

Transfected and infected cells were lysed with ProteoJET mammalian cell lysis reagent (Fermentas, Canada). Equal amounts of total proteins were subjected to electrophoresis on $12 \%$ SDS-PAGE and electrophoretically transferred to a nitrocellulose membrane using manufacturer's protocol (Bio-Rad, USA). Blots were incubated with specific-monoclonal antibodies of HCV Core, Cox2, VEGF, p-Akt and GAPDH (Santa Cruz Biotechnology, Inc, USA). Proteins expression was evaluated using Chemiluminescence's detection kit (Sigma Aldrich, USA). For protein quantifications X-ray films were scanned and fold inductions were calculated by densitometer analysis.

\section{Statistical Analysis}

All statistical analysis was performed by using SPSS software (version 16.0, SPSS Inc). Data are presented as mean \pm SD. Numerical data were analyzed using student's t-test and ANOVA. $P$ value $<0.05$ was considered statistically significant.

\section{Additional material}

Additional file 1: Supplemental Results. This file contains three experimental results as supporting data and has been mentioned in the text.

Additional file 2: Figure S1. Silencing of host cellular gene, Cox-2 show reduction in the expression of genes involved in HCV pathogenesis. Huh-7 cells were transfected with HCV-3a Core expression vector or mock-treated along with or without $10 \mu \mathrm{M}, 20 \mu \mathrm{M}$ and $40 \mu \mathrm{M}$ of Cox-2 siRNAs for 48 hrs. (A) Cox-2 siRNA (COXsi) reduced gene expression of Core induced Cox-2 measured through semi-quantitative PCR. (B) Silencing of Cox-2 gene at protein expression level was determined by Western blot analysis after 48 hrs transfection with mock (M), with and without siRNA (COXsi) and scramble siRNA (SC) in Huh-7 cells. Protein levels for GAPDH gene are also shown as internal control. (C) Effect of silencing of Cox-2 gene on the relative gene expression levels quantified by Real-Time PCR 48 hrs post transfection are shown as fold induction for Cox-2/iNOSNEGF genes. GAPDH was used as internal control for normalization. Three independent experiments were performed having triplicate samples. Error bars indicate, mean S.D, *p $<$ 0.01 verses Core.

Additional file 3: Figure S2. Combined effect of Cox-2 and HCV 3a Core siRNAs on intracellular PGE2 production and the Huh-7 cells proliferation. (A) Intracellular level of PGE2 was determined in Core transfected cells with and without Core, Cox-2 and in combination of both siRNAs, using Biotrak prostaglandin Enzyme immunoassay system according to manufacturer's protocol. (B) Inhibition of Huh-7 cells proliferation was observed in Core transfected cells with and without Core, Cox-2 and in combination of both siRNAs by using MTT assay. Three independent experiments were performed having triplicate samples. Error bars indicate mean S.D, ${ }^{*} \# p<0.001,{ }^{*} p<0.01$ verses Core. Additional file 4: Figure S3. HCV 3a sera infection increases expression of genes involved in HCV pathogenesis as compared with HCV 1a sera. (A) Huh-7 cells were infected with high titer sera samples from HCV patients, either HCV-3a or HCV-1a genotype for $72 \mathrm{hrs}$. RNA expression levels as relative fold induction to normal sera are shown for Cox-2, iNOS and VEGF genes. (B) The protein expression levels were determined by Western blot analysis from Huh-7 cell lysates infected with HCV-1a (S1a), 3a (S3a) serum compared to normal and effect on Cox-2, VEGF and p-Akt expression using specific antibodies. Protein levels 
for GAPDH gene are shown as internal control. Three independent experiments with triplicate determinations were performed. Error bars indicate mean S.D, ${ }^{*} p<0.01$ verses serum 1 a.

\section{List of abbreviations}

HCV: Hepatitis C; RNAi: RNA interference; siRNAs: small interfering RNAs; HCC: hepatocellular carcinoma.

\section{Acknowledgements}

Financial support by Higher Education Commission (Grant \# 863) is highly acknowledged.

\section{Authors' contributions}

SJ, SK, BI, WA prepared, wrote manuscript and performed lab work. BI, WA and $\mathrm{SH}$ prepared final version of manuscript. SH was also principal investigator and provides support and facilities to complete this work. All authors approved the manuscript.

\section{Authors' information}

Shah Jahan (PhD molecular Biology) and Saba Khaliq (PhD molecular Biology) are both PhD scholars, Bushra ljaz (M Phil Molecular Biology) and Waqar Ahmad (M Phil Chemistry) are Research Officer, while Sajida Hassan (PhD Molecular Biology) is Principal Investigator at CEMB, University of the Punjab, Lahore.

\section{Competing interests}

The authors declare that they have no competing interests.

Received: 1 December 2010 Accepted: 1 April 2011

Published: 1 April 2011

\section{References}

1. Giannini C, Brechot C: Hepatitis C virus biology. Cell Death Differ 2003, 10 S27-S38.

2. Raja NS, Janjua KA: Epidemiology of hepatitis $C$ virus infection in Pakistan. J Microbiol Immunol Infect 2008, 41:4-8.

3. Ahmad W, ljaz B, Javed FT, Jahan S, Shahid I, Khan FM, et al: HCV genotype distribution and possible transmission risks in Lahore, Pakistan. World J Gastroenterol 2010, 16:4321-4328.

4. Okuda M, Li K, Beard MR, et al: Mitochondrial injury, oxidative stress, and antioxidant gene expression are induced by hepatitis $C$ virus core protein. Gastroenterology 2002, 122:568-57/1.

5. Moriya K, Fujie $H$, Shintani $Y$, Yotsuyanagi $H$, Tsutsumi $T$, Ishibashi $K$, et al: The core protein of hepatitis $C$ virus induces hepatocellular carcinoma in transgenic mice. Nat Med 1998, 4:1065-1067.

6. Tardif KD, Waris $G$, Siddiqui A: Hepatitis $C$ virus, ER stress, and oxidative stress. Trends Microbiol 2005, 13:159-163.

7. Nunez O, Fernandez-Martinez A, Majano PL, Apolinario A, GomezGonzalo M, Benedicto I, et al: Increased intrahepatic cyclooxygenase 2, matrix metalloproteinase 2, and matrix metalloproteinase 9 expression is associated with progressive liver disease in chronic hepatitis $C$ virus infection: role of viral core and NS5A proteins. Gut 2004, 53:1665-1672.

8. Koga H, Sakisaka S, Ohishi M, Kawaguchi T, Taniguchi E, Sasatomi K, et al: Expression of cyclooxygenase-2 in human hepatocellular carcinoma: relevance to tumor dedifferentiation. Hepatology 1999, 29:688-696.

9. Rahman MA, Kohno H, Nagasue N: COX-2 - a target for preventing hepatic carcinoma? Expert Opin Ther Targets 2002, 6:483-490.

10. Chiarugi V, Magnelli L, Gallo O: Cox-2, iNOS and p53 as play-makers of tumor angiogenesis. Int J Mol Med 1998, 2:715-719.

11. Cheng AS, Chan HL, To KF, Leung WK, Chan KK, Liew CT, et al: Cyclooxygenase-2 pathway correlates with vascular endothelial growth factor expression and tumor angiogenesis in hepatitis $B$ virus-associated hepatocellular carcinoma. Int J Oncol 2004, 24:853-860.

12. Tang TC, Poon RT, Lau CP, Xie D, Fan ST: Tumor cyclooxygenase-2 levels correlate with tumor invasiveness in human hepatocellular carcinoma. World J Gastroenterol 2005, 11:1896-1902.
13. Leng J, Han C, Demetris AJ, Michalopoulos GK, Wu T: Cyclooxygenase-2 promotes hepatocellular carcinoma cell growth through Akt activation: evidence for Akt inhibition in celecoxib-induced apoptosis. Hepatology 2003, 38:756-768.

14. Testa JR, Bellacosa A: AKT plays a central role in tumorigenesis. Proc Natl Acad Sci USA 2001, 98:10983-10985.

15. Vivanco I, Sawyers CL: The phosphatidylinositol 3-Kinase AKT pathway in human cancer. Nat Rev Cancer 2002, 2:489-501.

16. Vidali M, Stewart SF, Albano E: Interplay between oxidative stress and immunity in the progression of alcohol-mediated liver injury. Trends $\mathrm{Mol}$ Med 2008, 14:63-71.

17. Khaliq S, Jahan S, ljaz B, Ahmad W, Asad S, Pervais A, et al: Inhibition of Core gene of HCV 3a genotype using synthetic and vector derived siRNAs. Virology J 2010, 7:318.

18. Idrees M, Rafique S, Rehman I, Akbar H, Yousaf MZ, Butt S, et al: Hepatitis C virus genotype $3 a$ infection and hepatocellular carcinoma: Pakistan experience. World J Gastroenterol 2009, 15:5080-5085.

19. Raza SA, Clifford GM, Franceschi S: Worldwide variation in the relative importance of hepatitis $B$ and hepatitis $C$ viruses in hepatocellular carcinoma: a systematic review. Br J Cancer 2007, 96:1127-1134.

20. Tachi $Y$, Katano $Y$, Honda $T$, Hayashi K, Ishigami M, Itoh A, et al: Impact of amino acid substitutions in the hepatitis $C$ virus genotype $1 \mathrm{~b}$ core region on liver steatosis and hepatic oxidative stress in patients with chronic hepatitis C. Liver Int 2009, 30:554-559.

21. Jackel-Cram C, Babiuk LA, Liu Q: Up-regulation of fatty acid synthase promoter by hepatitis $C$ virus core protein: genotype-3a core has a stronger effect than genotype-1b core. J Hepatol 2007, 46:999-1008.

22. Zhao QT, Yue SQ, Cui Z, Wang Q, Cui X, Zhai HH, et al: Potential involvement of the cyclooxygenase- 2 pathway in hepatocellular carcinoma-associated angiogenesis. Life Sci 2007, 80:484-492.

23. Bamba H, Ota S, Kato A, Kawamoto C, Fujiwara K: Prostaglandins upregulate vascular endothelial growth factor production through distinct pathways in differentiated U937 cells. Biochem Biophys Res Commun 2000, 273:485-491.

24. Gallo O, Franhi A, Magnelli L, Sardi I, Vannacci A, Boddi V, et al: Cyclooxygenase-2 pathway Correlates with VEGF expression in head and neck cancer. Implications for tumor angiogenesis and metastasis. Neoplasia 2001, 3:53-61.

25. Hu Z, Muroyama R, Kowatari N, Chang J, Omata M, Kato N: Characteristic mutations in hepatitis virus core gene related to the occurrence of hepatocellular carcinoma. Cancer Sci 2009, 100:2465-2468.

26. Pazienza V, Vinciguerra M, Andriulli A, Mangia A: Hepatitis C Virus core protein genotype $3 a$ increases SOCS-7 expression through PPAR\{gamma\} in Huh-7 cells. J Gen Virol 2010, 91:1678-1686.

27. Hourioux C, Patient R, Morin A, Blanchard E, Moreau A, Trassard S, et al: The genotype 3 -specific hepatitis $C$ virus core protein residue phenylalanine 164 increases steatosis in an in vitro cellular model. Gut 2007 , 56:1302-1308

28. Jhaveri R, McHutchison J, Patel K, Qiang G, Diehl AM: Specific polymorphisms in hepatitis $C$ virus genotype 3 core protein associated with intracellular lipid accumulation. J Infect Dis 2008, 197:283-291.

29. Mann AE, Stanford S, Sherman EK: Prevalence of mutations in hepatitis $C$ virus core protein associated with alteration of NF-kB activation. Virus Research 2006, 121:51-57.

30. Nunez O, Fernandez-Martinez A, Majano PL, Apolinario A, GomezGonzalo M, Benedicto I, Lopez-Cabrera M, Bosca L, Clemente G, GarciaMonzon C, Martin-Sanz P: Increased intrahepatic cyclooxygenase, matrix metalloproteinase, and matrix metalloproteinase expression is associated with progressive liver disease in chronic hepatitis C Virus infection: role of viral core and NS5A proteins. Gut 2004, 53:1665-1672.

31. Akuta N, Suzuki F, Hirakawa M, Kawamura Y, Yatsuji $H$, Sezaki $H$, et al: Amino acid substitutions in the hepatitis $C$ virus core region of genotype $1 \mathrm{~b}$ are the important predictor of severe insulin resistance in patients without cirrhosis and diabetes mellitus. J Med Virol 2009, 81:1032-1039.

32. Akuta N, Suzuki F, Sezaki H, Suzuki Y, Hosaka T, Someya T, et al: Association of amino acid substitution pattern in core protein of hepatitis $C$ virus genotype $1 \mathrm{~b}$ high viral load and non-virological response to interferonribavirin combination therapy. Intervirology 2005, 48:372-380.

33. Donlin MJ, Cannon NA, Yao E, Li J, Wahed A, Taylor MW, et al: Pretreatment sequence diversity differences in the full-length hepatitis $C$ 
virus open reading frame correlate with early response to therapy. J Virol 2007, 81:8211-8224.

34. Kim M, Shin D, Kim SI, Park M: Inhibition of hepatitis C virus gene expression by small interfering RNAs using a tri-cistronic full-length viral replicon and a transient mouse model. Virus Res 2006, 122:1-10.

35. Liu M, Ding H, Zhao P, Qin ZL, Gao J, Cao MM, et al: RNA interference effectively inhibits mRNA accumulation and protein expression of hepatitis $\mathrm{C}$ virus core and E2 genes in human cells. Biosci Biotechnol Biochem 2006, 70:2049-2055.

36. Buck M: Direct infection and replication of naturally occurring hepatitis $C$ virus genotypes 1,2, 3 and 4 in normal human hepatocyte cultures. PLoS One 2008, 3:e2660.

37. el-Awady MK, Tabll AA, el-Abd YS, Bahgat MM, Shoeb HA, Youssef SS, et al: HepG2 cells support viral replication and gene expression of hepatitis $C$ virus genotype 4 in vitro. World J Gastroenterol 2006, 12:4836-4842.

38. Lazaro CA, Chang M, Tang W, Campbell J, Sullivan DG, Gretch DR, et al: Hepatitis $C$ virus replication in transfected and serum-infected cultured human fetal hepatocytes. Am J Pathol 2007, 170:478-489.

39. Molina S, Castet V, Pichard-Garcia L, Wychowski C, Meurs E, Pascussi JM, et al: Serum-derived hepatitis $C$ virus infection of primary human hepatocytes is tetraspanin CD81 dependent. J Virol 2008, 82:569-574.

40. Zekri AR, Bahnassy AA, El-Din HM, Salama HM: Consensus siRNA for inhibition of HCV genotype-4 replication. Virol J 2009, 6:13.

41. Khaliq S, Jahan S, Ijaz B, Ahmad W, Asad S, Hassan S: Inhibition of HCV 3a genotype by siRNAs targeting envelope genes. Arch Virol 2010, 156(3):433-442.

42. Henry SD, van der WP, Metselaar HJ, Tilanus HW, Scholte BJ, van der Laan $\mathrm{L}$ : Simultaneous targeting of HCV replication and viral binding with a single lentiviral vector containing multiple RNA interference expression cassettes. Mol Ther 2006, 14:485-493.

43. Korf M, Jarczak D, Beger C, Manns MP, Kruger M: Inhibition of hepatitis C virus translation and subgenomic replication by siRNAs directed against highly conserved HCV sequence and cellular HCV cofactors. J Hepatol 2005, 43:225-234.

44. Nakagawa S, Umehara T, Matsuda C, Kuge S, Sudoh M, Kohara M: Hsp90 inhibitors suppress HCV replication in replicon cells and humanized liver mice. Biochem Biophys Res Commun 2007, 353:882-888.

45. Randall G, Grakoui A, Rice CM: Clearance of replicating hepatitis C virus replicon RNAs in cell culture by small interfering RNAs. Proc Natl Acad Sci USA 2003, 100:235-240.

46. Song E, Lee SK, Wang J, Ince N, Ouyang N, Min J, et al: RNA interference targeting Fas protects mice from fulminant hepatitis. Nat Med 2003, 9:347-351.

47. Zender L, Hutker S, Liedtke C, Tillmann HL, Zender S, Mundt B, et al: Caspase 8 small interfering RNA prevents acute liver failure in mice. Proc Natl Acad Sci USA 2003, 100:7797-7802.

48. Lemon SM, Lerat H, Weinman SA, Honda M: A transgenic mouse model of steatosis and hepatocellular carcinoma associated with chronic hepatitis C virus infection in humans. Trans Am Clin Climatol Assoc 2000, 111:146-156.

49. Lerat $H$, Honda $M$, Beard MR, et al: Steatosis and liver cancer in transgenic mice expressing the structural and nonstructural proteins of hepatitis $\mathrm{C}$ virus. Gastroenterology 2002, 122:352-365.

50. Ohata $\mathrm{K}$, Hamasaki $\mathrm{K}$, Toriyama $\mathrm{K}$, et al: Hepatic steatosis is a risk factor for hepatocellular carcinoma in patients with chronic hepatitis $\mathrm{C}$ virus infection. Cancer 2003, 97:3036-3043.

51. Moriya K, Yotsuyanagi $H$, Shintani $Y$, Fujie $H$, Ishibashi $K$, Matsuura $Y$, Miyamura T, Koike $\mathrm{K}$ : Hepatitis $\mathrm{C}$ virus core protein induces hepatic steatosis in transgenic mice. J Gen Virol 1997, 78:1527-1531.

52. Kato T, Miyamoto M, Date T, et al: Repeated hepatocyte injury promotes hepatic tumorigenesis in hepatitis $\mathrm{C}$ virus transgenic mice. Cancer Sci 2003, 94:679-68.

\section{doi:10.1186/1743-422X-8-155}

Cite this article as: Jahan et al:: Role of HCV Core gene of genotype 1a and $3 \mathrm{a}$ and host gene Cox-2 in HCV-induced pathogenesis. Virology Journal 2011 8:155.

\section{Submit your next manuscript to BioMed Central and take full advantage of:}

- Convenient online submission

- Thorough peer review

- No space constraints or color figure charges

- Immediate publication on acceptance

- Inclusion in PubMed, CAS, Scopus and Google Scholar

- Research which is freely available for redistribution

Submit your manuscript at www.biomedcentral.com/submit
Biomed Central 